\title{
Teaming up helps bring down
}

The statistics are alarming: the prevalence of overweight children has tripled over the last 30 years, and now affects one in six school-aged children nationwide. But while the problem is plain to see, the remedy has been elusive. Recent studies by UC researchers and others reveal that the rise in childhood obesity is rooted in fundamental social changes, explaining why this epidemic is so hard to control as well as bringing us closer to a solution.

"We used to think the primary cause was parenting, then we thought it was genetic," says Pat Crawford, co-director of UC Berkeley's Center for Weight and Health. "But neither could explain the rapid increase in childhood obesity - we found that a significant fraction is environmental."

Children are considered to be overweight when their body mass index (weight divided by height squared) is at or above the 95th percentile for their age. Half of overweight children continue to be overweight as adults, increasing their risk of illnesses including diabetes, cardiovascular disease and asthma (see page 119).

\section{Environmental changes}

Weight gain is a simple equation of calories consumed minus calories burned. But achieving a healthy weight is not so easy these days, when there are more opportunities for eating than for exercising (see page 112).

The changes in children's lifestyles have been particularly acute. Compared to the early 1970s, families today spend about twice as much on eating out, and children ingest almost twice as many calories when they eat in restaurants as when they eat at home. While this change bumps up the "calories consumed" part of the equation, other changes bring down the "calories burned" part. "We spend lots of time sitting in cars and at desks," says Susan Babey of the UCLA Center for Health Policy Research. "And we can't walk to many places." Today only a quarter as many children walk or bike to school compared to a few decades ago.

The impact is worst in the poorest neighborhoods, where children are most likely to be overweight (see page 106). For example, as the number of low-income households rises, teens' access to safe parks and physical activity levels drop, according to a March 2007 UCLA Health Policy Research Brief co-authored by Babey. Other neighborhood characteristics linked to low physical activity in teens include high unemployment and household overcrowding.
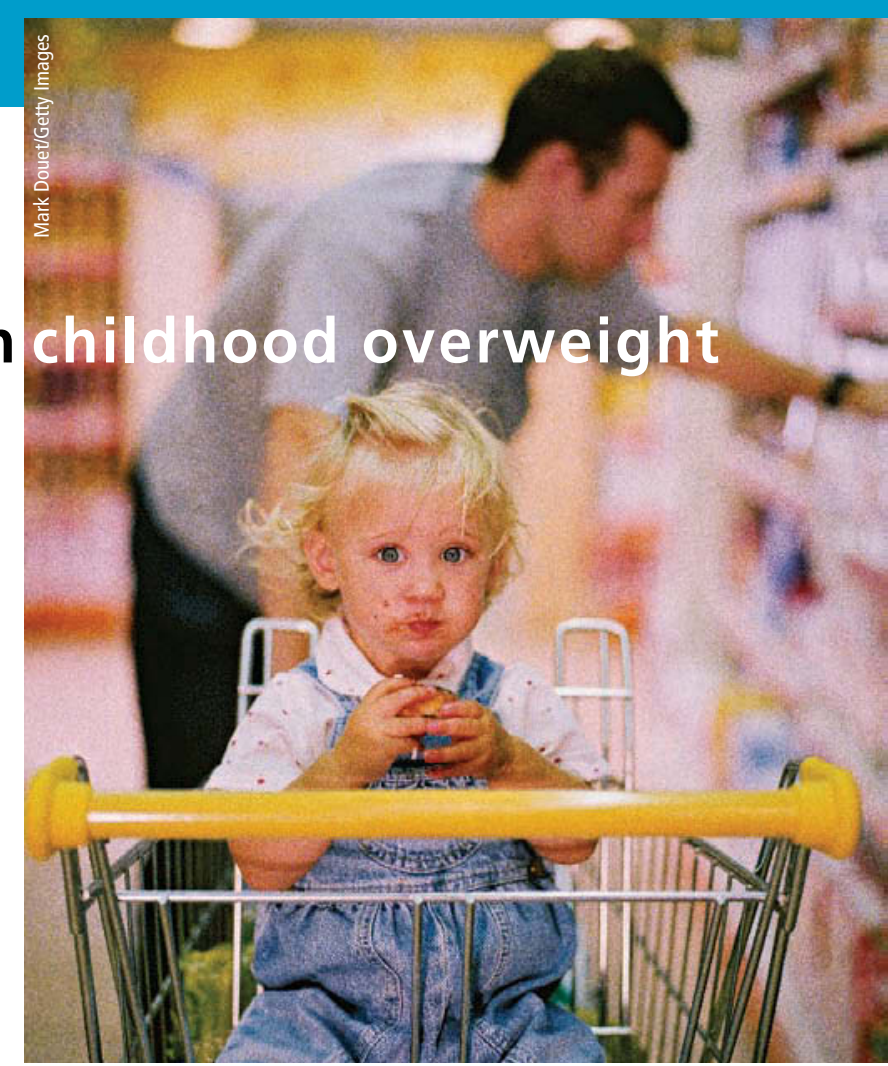

Since the 1970s, children have been consuming more calories and getting less exercise. The result has been an epidemic of childhood overweight.

While home environments can be difficult to change, children can also be reached through schools. Unfortunately, many physical education classes today aren't really that physical. For every half-hour of P.E., children are vigorously active for only 4 minutes, according to a January 2007 policy brief commissioned by The California Endowment and co-authored by Toni Yancey, co-director of the UCLA School of Public Health's Center to Eliminate Health Disparities. Again, the impact is worst in the poorest communities.

Besides contributing to children's low physical activity levels, schools are exacerbating the other part of the weight-gain equation. UC studies have shown that many schools are full of fast food and soda, tempting children to consume too many empty calories (see page 124).

\section{Can legislation help?}

Now UC researchers are evaluating California legislation designed to fix this problem, such as SB 281, which mandates more fresh fruits and vegetables at school breakfasts. Encouragingly, offerings of fresh fruit have more than doubled, according to a preliminary study by the Center for Weight and Health.

"Promoting fresh produce is good for children's health and for the California economy." says Gail Woodward-Lopez, the center's associate director. 


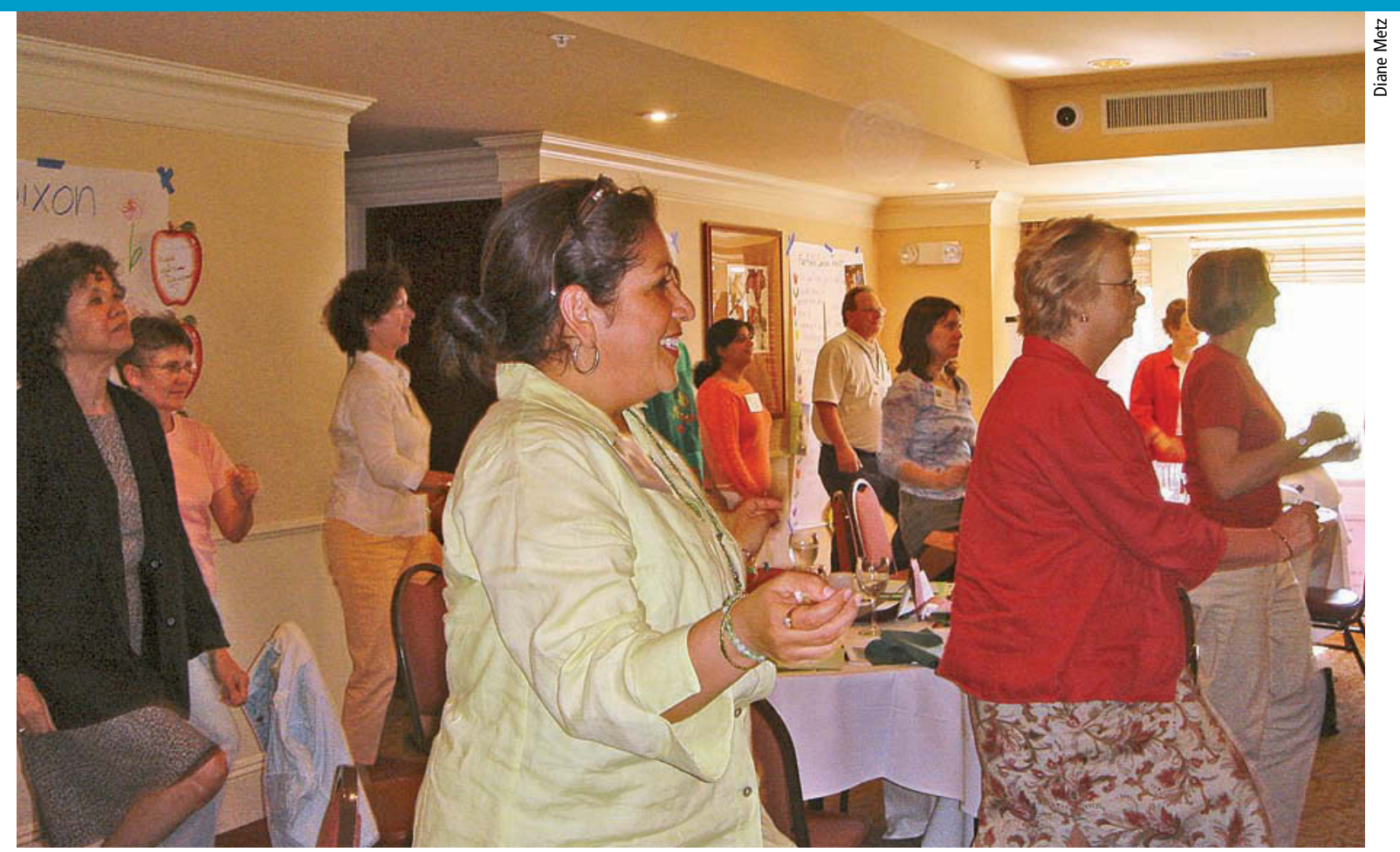

Community leaders participating in the Children and Weight Coalition of

Solano County (see page 124) learn about how they can encourage families and children to adopt healthier lifestyles.

The Center for Weight and Health is also evaluating SB 12, which limits school sales of high-fat and high-sugar foods beginning this summer, and SB 965, which completely phases out school sales of soda and other high-sugar beverages over the next 2 years in California. "We will be assessing factors such as the extent of implementation, challenges school districts face and students' dietary intakes," Woodward-Lopez says.

\section{Community-based approaches}

Organizations are also trying to reach children outside of school via community health initiatives. These include two initiatives with almost identical names, which is not surprising considering that they also have similar goals: Healthy Eating Active Living (HEAL), which is sponsored by Kaiser Permanente (see page 124); and Healthy Eating, Active Communities (HEAC), sponsored by The California Endowment, a private health foundation with additional funding from Kaiser Permanente.

UC is part of a team evaluating HEAC in six California communities, with UCLA focusing on physical activity and UC Berkeley on nutrition. The Center for Weight and Health is also part of the team evaluating HEAL in three California communities. "These are the first comprehensive, communitywide interventions of their kind," Crawford says.

To further inform efforts to promote healthy eating and exercise habits among children, UCLA researchers are updating their evaluation of the status of childhood obesity statewide. This will include monitoring weight trends and assessing the many factors implicated in the rise in obesity. The update is part of the California Health Interview Survey, which has been conducted every 2 years since 2001 by the UCLA Center for Health Policy Research, the California Department of Health Services, and the Public Health Institute, a national nonprofit organization.

All the pieces come together at the California Childhood Obesity conferences, which focus on preventing excess weight gain in children. The conferences are organized by the Center for Weight and Health, the California Department of Health Services,
For more information:

UC Berkeley Center for Weight and Health http://nature.berkeley.edu/cwh
Education, and The California Endowment. Since the first conference in 2001, to the most recent one held earlier this year in Anaheim, the participants have expanded from nutritionists and health care professionals to also include educators, city planners, and park and recreation officials.

Involving everyone is crucial to stopping and maybe even reversing the childhood obesity epidemic. "We can't say there are too many factors, that it's too complex," Crawford says. "If we don't act, the rate of childhood obesity will be quadrupled soon." — - Robin Meadows 